\title{
Psychosocial Foundations for Pedagogical Skills Formation of Future Specialists in the Special Educational Environment
}

\author{
Roza Sh. Sydykova,"\#,*, Adalyat A. Yussupova ${ }^{2, \#}$, \\ Torgyn A. Smailova ${ }^{2, \#}$ and Nauryz T. Kuldanov ${ }^{3, \#}$ \\ ${ }^{1}$ Akhmet Yassawi International Kazakh-Turkish University, Turkestan, Republic of Kazakhstan \\ ${ }^{2}$ Kurmangazy Kazakh National Conservatory, Almaty, Republic of Kazakhstan \\ ${ }^{3}$ Abai Kazakh National Pedagogical University, Almaty, Republic of Kazakhstan
}

Galimzhan K. Berekeshev,"\#,

\begin{abstract}
Objective: The main goal of the work is to analyse future music teachers' pedagogical process and its impact on the creative potential of the individual.

Background: Pedagogical work has always been creative since its main purpose is to build, create a personality, develop, affirm the spiritual principle in a person. In addition, the activities of a teacher are carried out in constantly changing situations, requires consideration of all conditions. Therefore, the main task of a teacher is to transfer his creative potential with special educational needs.

Method: theoretical methods were used for research, which allowed us to determine the role of music in students' development.

Results: It was established that the formation of artistry in the process of teaching vocals is understood as a complex motivational-semantic education. It has been determined that the strength of the students' spiritual attraction to their mentor largely depends on the presence in his individual appearance of such a purely personal quality as an attraction, introduced by psychologists in scientific use for more in-depth ideas about the artistic and communicative possibilities of a person.

Conclusion: The results of the study made it possible to determine that an integrated approach to musical and pedagogical activity helps to solve pedagogical problems using musical art tools that combine a complex of special, psychological and pedagogical, general scientific, methodological knowledge, skills with the leading role of general pedagogical abilities.
\end{abstract}

Keywords: Creativity, aesthetic cycle, pedagogical process, artistically gifted personality.

\section{INTRODUCTION}

In the last decade, a powerful movement in psychiatry has been forming in many countries, in which various public organisations, associations of patients and their relatives, and charitable foundations play an important role. The main task of these associations is to provide a variety of assistance, support the mentally ill, and protect their rights and interests. One of the priority tasks in pedagogical science is the formation and development of music teachers' creative personality. This is due to the strengthening role of art in the education of the future generation, the involvement of various forms, methods, and means of artistic training and education for the realisation of this goal [1]. Especially when training people with psychological disorders.

Today, psychiatry has gone beyond the traditional framework that had previously been limited to

${ }^{*}$ Address correspondence to this author at the Akhmet Yassawi International Kazakh-Turkish University, Turkestan, Republic of Kazakhstan;

Tel: +7 702669 7353; E-mail: rosa.sydykova@nuos.pro

\#These authors are equally contributed. psychiatric hospitals, dispensaries, and patients' contingent. Today, psychiatrists work in large somatic hospitals, clinics, educational institutions, medical units, departmental medical institutions, schools, and universities. Among the population, in educational, industrial, and other teams, psychiatrists perform not only medical and diagnostic work, but also solve many social problems, ethical, legal, expert issues, participate in the development of programs for a healthy lifestyle of the population, and prevention of mental disorders. And many teachers need to be prepared for the fact that there are schoolchildren, students who have psychological characteristics. These people need a special approach. One of the important directions in psychological therapy is music $[2,3]$. Attempts to describe the impact of music on human health have been many since the ancient times of the legendary Orpheus. If health is understood as a mental or psychic state, then this connection is obvious and does not require evidence.

Even in antiquity, music was separated from the rest of the arts. According to ancient scholars, it obeyed some objective laws and existed regardless of 
a person. Pythagoras was the first to describe in mathematical terms what notes are, as well as pleasant and unpleasant sounds. Pythagoras treated many diseases of a spirit, soul, and body, playing special musical compositions composed by him. It is known that the Pythagoreans used special melodies against rage and anger. At the same time, it is obvious that in the field of correctional practice, efforts must be made to bring the positions of the medical and psychologicalpedagogical sciences closer [4]. This is most successful in pedagogical music therapy. It is a new field of knowledge that should integrate the achievements of medicine, psychology, general and corrective pedagogy, musicology, musical psychology, theory, and methodology of musical training and education. The concept of artistry is multi-perspective and multidimensional. At each new phase of its evolution, there is an expansion of conceptual semantic content, supplemented by current modern trends, characteristics, and requirements, students' particularities. The phenomenon of artistry is becoming increasingly attractive for the complex of modern humanities. The aestheticising of all social life involves the spread of behaviours and activities that are identified as artistic manifestations [5].

In the aforesaid context, the low level of motivation of students with psychological disorders and their lack of auditory experience in the cultural tradition of academic vocal singing requires the development of new effective vocal and pedagogical technologies for developing artistic skills in the discipline "Vocal". This moment serves as a motivator for pedagogical assessment, which should be realised through a system of indicators that record and describe the processes of the so-called "artistically delivered vocal speech". In developing the creative abilities of students with psychological disabilities in the context of innovative education, the creative components in the preparation are not of an artisan, but an innovator, a creative thinker who has a well-developed emotional sphere. It is important to emphasise that human artistry is based on figurative associations, associated with shades of thoughts, empathy.

The role of music perception in musical culture is multifaceted and comprehensive: firstly, this is the ultimate goal of music-making, to which the work of a composer and performer is directed; secondly, it is a means of selecting and consolidating certain compositional techniques, stylistic finds and discoveries - that which is accepted by the perceiving consciousness of the public, becomes a part of the musical culture, takes root in it; and finally, musical perception is what unites all types of musical activity from the first steps of a student to the mature works of a composer [6]. For each style, for each type and genre of music, this or that way of perception is characteristic: psychological attitudes, the focus of attention, and manner of behaviour are different. And therefore, a teacher must be able to adapt to the psychological characteristics of each student. At the same time, there are significant individual differences in the perception of even the same styles or musical compositions that are close to each other: each listener uses his own perception strategies, each interprets and decrypts the content of a musical work in his own way, and these differences, which can be called subjective, make the musical perception truly unique.

What psychological mechanisms are the instrument, the foundation of musical perception? How is the interpretation of the psychic "imprint" of the music heard, a kind of combination of sound and meaning, the fusion of sound and aesthetic principles of musical art? The study of musical perception seeks answers to these and other similar questions, and it is primarily aimed at studying the methods and operations that consciousness uses during the multilateral and complicated process of transforming a collection of auditory stimuli into a phenomenon of musical culture. Modern cultural reality is characterised by an incredible multiplicity of cultural products that are offered to a reader, viewer, and listener. Based on the foregoing, the main purpose of the work is to analyse special approaches to teaching music for students with psychological disabilities.

\section{MATERIALS AND METHODS}

To better understand the psychological roots of certain qualities and properties of musical perception in adults, to understand from which components and how these qualities appear, it is natural to turn to the ontogenetic evolution of the ability of musical perception. The characteristics of the main stages of development coincide among many authors and are reduced to the gradual formation of mature conceptual thinking in a student. This process underlies absolutely all changes taking place in the psyche, whether it concerns the properties of speech, perception, or creativity in any field. The first stage on this path can be called the stage of single signs that pull together a holistic image of $s$ subject. Orientation to a single sign (in music, it can be a song text, a characteristic timbre, rhythmic pattern) distinguishes thinking in any activity. 
So, the formation of the sphere of musical perception among schoolchildren should come primarily from their inherent psychophysiological features and properties. Given the age specifics, a teacher should build the socalled upbringing and developmental education, which, according to the well-known didactic postulate, should lead the child's mental development, play a leading role in this process, determining its main directions, including those related to music perception.

After analysing various sources, it was found that there are two main approaches to the treatment with the music: the first is passive listening, aimed at relaxing the nervous system. The second is the socalled vocal therapy, i.e., singing therapy, which involves creative aspects of music perception. Engaged in singing according to a special program, a patient undergoes two healing effects at once: on the one hand, singing strengthens the respiratory and cardiac systems, and on the other, positively "charges" the nervous system. Music therapy is combined with dance therapy, with relaxation and body-oriented techniques, with art therapy. A teacher needs to take into account the characteristics of each child and in their lessons, based on this, apply an active or passive type of psychotherapy. Currently, there are many studies on the influence of music and music lessons not only on the emotional state but also on human behaviour. Even the lack of consciousness is not an obstacle to the impact of music. There are often cases when people come out of a coma if they play a melody or song that is emotionally meaningful.

The famous neurologist Oliver Sacks identified the most successful music therapy techniques for working with neurological patients:

- playing simple musical instruments, "conversation" - interaction through sounds with mentally disabled children and children with severe forms of autism

- music training for children with Asperger, Down, and Williams syndromes to overcome the difficulties of adaptation and communication

- $\quad$ singing familiar songs, listening to your favourite tunes for patients with gross memory and identity

- movement to music with a clear rhythm for patients with motor impairments, motor tics (Parkinson's disease, Tourette's syndrome, rehabilitation after strokes)
- $\quad$ work with stuttering, music therapy of aphasia through singing to actualise the compensatory mechanisms of the brain

The therapeutic effect of music depends on its nature, so not every teacher can use music therapy correctly. The analysis method allowed determining that one of the advantages of music therapy is the lack of the need to mediate the internal state of speech. This is significant if a patient has communicative difficulties or speech problems (for example, an autism spectrum disorder or dementia).

The problem of adaptation is interdisciplinary and occupies a significant place in the research of both domestic and foreign psychologists and teachers. As is known, the term "adaptation" was introduced into psychological science from biological disciplines. So, for example, in physiology, this term means the reaction of the adaptation of sensory organs with respect to the effects of relevant stimuli, and in biology, the adaptation of the structure of the functions of organs to the conditions of the organism. The problem of adaptation remains relevant in psychological concepts, which are aimed at analysing the relationship of an individual with the environment. At the level of pedagogical and psychological-pedagogical analysis, the adaptation process is mainly associated with the inclusion of a subject in a new educational situation and serves as an indicator of the training success. In studying the question posed, a study was conducted that was based on researching the influence of different music styles on students. The experiment was attended by 23 second-year students of Akhmet Yassawi International Kazakh-Turkish University in Almaty.

The integral coefficient of well-being before and after listening was calculated by the formula:

$F A M=(F+A+M): 3$.

$\mathrm{F}$ - feeling; $\mathrm{A}$ - the degree of activity; $\mathrm{M}$ - mood.

Music therapy can help a person not only in the treatment of diseases but also in pedagogy, as well as in the process of socialisation. To do this, it is necessary to determine what is the biological algorithm for the positive impact of music on various systems of a human body. In a simple form, this mechanism looks like this: music, evokes positive emotions; they turn off some chemical reactions that are harmful to a body, turn on the release of positive secrets such as serotonin, as a result of which a kind of therapy occurs. 
The following forms of music therapy are distinguished: receptive, active, integrative. Receptive (passive) music therapy is characterised in that a patient actively participates in the music therapy session, taking the position of a simple listener. He is offered to listen to various musical compositions or to listen to various sounds (consonances) that correspond to a state of his mental health and a stage of treatment.

Active methods of music therapy are based on active work with musical material: instrumental playing, singing. Integrative music therapy takes advantage of other forms of art, organically integrating with them: drawing to music, music-moving games, plastic dramatisation to music, creating poems, drawings, stories on this musical theme and other creative forms. Musical therapeutic methods are selected, as a rule, individually. There are four main therapeutic effects of music therapy:

- emotional activation during verbal
psychotherapy;

- development of interpersonal communication skills; that is, communicative functions and abilities. According to Schwabe's theory, the communicative form consists of listening to music together to create an atmosphere of mutual trust between a doctor and a patient;

- $\quad$ regulatory influence on psycho-vegetative
processes;

- $\quad$ increasing the aesthetic needs of a person.

The mechanisms of the therapeutic effect of music therapy include: catharsis, emotional discharge, regulation of the emotional state, facilitating the realisation of the reasons for one's own experiences, reducing confrontation with life problems, increasing social activity, acquiring new means of expressing emotional expression, facilitating the formation of new social relationships and attitudes.

Genuine artistry is an expression of a person's rich inner world, including a music teacher. This phenomenon is defined as the multifaceted and complex quality of the universal order, necessary for almost every person, regardless of their professional activities. According to V.I. Zagvyazinsky, contributes to successful communication, brings an element of novelty and creativity to professional activities, optimises life in many of its manifestations. Moreover, several scientists believe that artistry is such a quality, the possession of which ensures the freedom of personal expression, the freedom of creativity in the broad sense of the term, the richness of personal manifestations, the imaginative way of posing and solving problems, the game of imagination, grace, spirituality, a sense of inner freedom, and not only external factors - gestures, facial expressions, intonation [7].

\section{RESULTS}

It is well known that the identification of psychogenic factors in the development of diseases is an indication for the appointment of psychotherapeutic measures. At the same time, there are remain open questions of the search for methods that, to one degree or another, unite the influence on the mental, psychic and physical level of a person's existence and, thus, allow individual psychosomatic harmonisation of a person from the standpoint of a whole organism. At the same time, the problem of not only scientific justification but also the practical implementation of these methods in the activities of health care institutions is always relevant. The latter would have as their goal to fulfil the role of both preventive rehabilitation at the stages of the absence of any structural pathological changes ("tuning" the body at the pre-nosological stage) and an additional or independent type of therapy in the presence of diseases.

At the beginning of the 20th century, it was experimentally proved that musical sounds make every cell of a human body vibrate, electromagnetic waves affect the change in blood pressure, heart rate, rhythm, and depth of breath. Particularly intensively studied the influence of music in recent decades. Music therapy is gaining more and more popularity in modern medicine, along with herbal medicine and art therapy. It is about restoring human health through music lessons. The experiments are conducted in several directions:

- the impact of individual musical instruments on living organisms;

- the impact of the music of the great geniuses of mankind; the individual impact of individual works of composers;

- the impact on the human body of traditional folk trends in music, as well as modern trends.

Recently, scientists from the University of Nottingham in Germany conducted an interesting experiment: they tested on a group of volunteers the 
effectiveness of various means for sleeping and recording lullabies. To the surprise of experts, the melodies were much more effective than medicines: the test subjects had a deep and heavy sleep after them. In Russia, the Ministry of Health recognised music therapy as an official treatment method in 2003. The fact remains: music therapy is becoming a recognised science in the world. Moreover, in several Western universities today, they are training professional doctors who are involved in music. Educators - musicians need to keep up with current trends in science. Musical therapy, together with art therapy, can be an effective method of treating school neurosis, which today affects students more and more, both in obtaining education and modern life in general.

Rhythm has the most powerful and direct effect on a person - both on his body and emotions. The life of a body is based on various rhythms: breathing, heart, various movements, activity, and relaxation, not to mention more subtle rhythms at the level of cells and molecules. The rhythm of music during work can increase productivity and save strength. The psychological state of a person also has its own complicated rhythms: inspiration and depression, grief and joy, zeal and apathy, strength and weakness, etc. All these conditions are very sensitive to musical rhythms. Is it because they have such magic to arouse and soothe, heal and destroy.

The melody affects a listener, especially intensively and variably. It awakens not only emotions but also sensations, images, and beliefs, strongly affect almost all life functions, especially the nervous system, respiration, and blood circulation. Due to various vibrations emitted by these chords, either a sense of harmony or dissonance arises in the soul of the audience, which in any case has a certain physical and psychological effect. The prevalence of dissonance in modern music is an expression of discord, conflict, crisis, which brings suffering to a modern human. For the effectiveness of music therapy, teachers use it according to certain rules, which are more based on psychophysiological principles than on aesthetic and artistic ones. Therefore, a teacher must consider the following points when teaching music to children with psychological disabilities:

- Before listening to a musical composition, it is necessary to study the information about work. It is worth knowing its essence and structure.

- It is necessary to alternate listening to music and discussion of composition itself. The treatment with music should be short enough so as not to cause fatigue and possible defensive reactions. This favours its complete, non-disturbing effect on the unconscious.

- The strength or volume of the music must be carefully adjusted. Low volume should be chosen not only for soothing but also for stimulating music. High volume tires and shakes the nervous system.

- The choice of music should be well thought out. It is much more complicated than it might seem at first glance. Sometimes it is necessary that principles that seem obvious are limited and even ignored. It would seem obvious to use soothing, stimulating, or cheerful music. However, everything is not so simple. Cheerful music can cause nervous tension.

Music impacts a brain structure, which is responsible for intuition, interaction with the outside world. E. Dalinskaya, a composer, talking about music therapy, believes that treatment with music is sometimes more effective than drugs that many are allergic to. Interestingly, the timbre of sounding instruments that have different therapeutic effects is of no small importance. For example, the piano removes excitability, calms the nervous system. Therefore, during lessons with children with psychological disorders, a teacher needs to play the piano to reduce nervous tension. Musical preferences, in many respects, depending on a person's temperament. But the most significant effect on patients, according to experts, is provided by Mozart's tunes. This musical phenomenon, not yet fully explained, was called the "Mozart effect". The secret of the beneficial effect of Mozart's music lies in the thirty-second sustained rhythm of "loud-quiet," which perfectly matches the nature of the brain's bioelectric currents. After a 10minute listening to Mozart's piano music, tests showed an increase in the so-called "intelligence coefficient" among students participating in the experiment by an average of 8-9 units. An interesting fact was that Mozart's music enhanced all participants' mental abilities in the experiment - both those who love Mozart and those who don't like it. Among the 2nd year students of Akhmet Yassawi International KazakhTurkish University, according to formula 1, a study was conducted on the impact of classical music on a person (Figure 1).

After classical music, 15 persons felt better, the degree of activity increased by 11 persons, and mood 


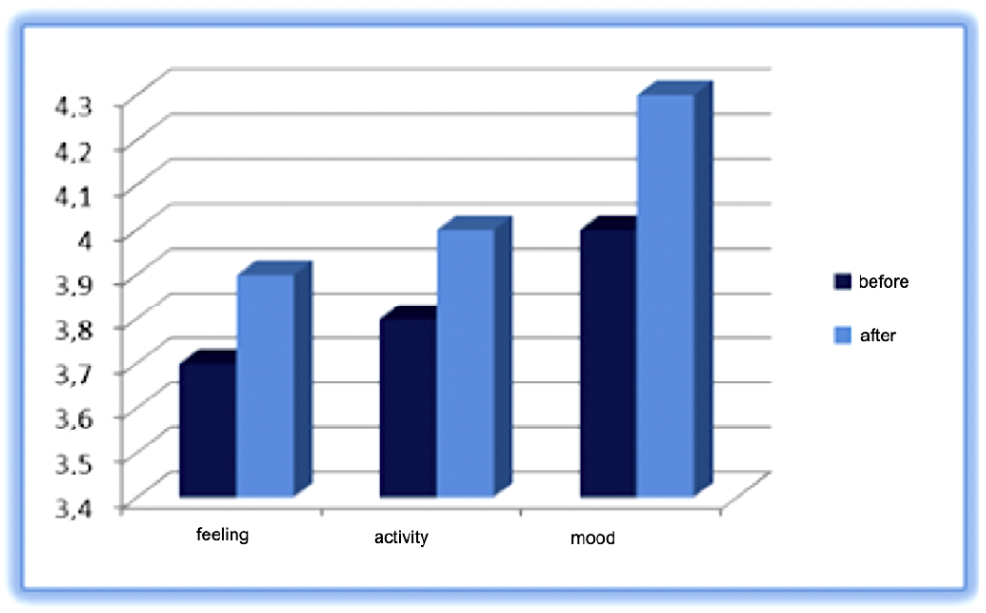

Figure 1: Testing results before and after listening to rock music.

improved in 12 persons. And after listening to rock music, the person's feeling remained the same, activity and mood increased slightly. According to the survey results, it can be concluded that the perception of classical music had a positive effect. A teacher with artistic skills inspires the content of the educational process and its organisation with his enthusiasm. This is a creative specialist with his special attitude, filled and intense inner life, "... acting contagious, exciting. This teacher knows how to find the only true, exact pedagogical solution that has a beneficial effect on a pupil" [8]. The ability to "present oneself" in the classroom in such a way as to arouse genuine interest on the part of students, flexibly building the figuratively emotional "instrumentation" of the pedagogical process, without difficulty entering the necessary role in the course of the development of a plot, based on the specific professional situation - these are the individual parameters of the existing ideas about the role of pedagogical artistry in working conditions at school. The teacher's aristocracy is also very important in the process of conveying the importance of classical music to people with psychological disorders. It is advisable to confirm this thesis with the remarks of O.A. Apraksina: "A teacher-lessor must completely give way to a teacher-innovator, acting not formally, but creatively purposefully. Therefore, it is necessary to constantly improve his skills, which are largely close to an actor's skills. The artistry of a teacher is not a dream, but an urgent need available to someone who really wants to develop this quality in himself" [8].

Today, among the many methods of sociopsychological adaptation of schoolchildren, art therapy ones are recognized as the most effective. Art therapy is a specialised form of psychotherapy based on art and creative activities. Its purpose is to develop self- expression and self-knowledge of a person through art to develop abilities for constructive actions with the outside world. Art-therapeutic methods are integrative and include in their arsenal artistic, pedagogical, psychotherapeutic, and medical methods, which, if used adequately by a teacher, can increase the reserve and adaptive capabilities of a human body. The range of problems for the solution of which art therapy methods can be used is quite wide: intra- and interpersonal conflicts; crisis conditions; existential and age-related crises; injuries, losses; post-stress disorders, neurotic disorders, psychosomatic disorders; personal integrity development; the discovery of personal meanings through creativity; psychoprophylaxis of antisocial behaviour, gambling, alcohol, and drug addiction; psychological adaptation and social rehabilitation of students. Currently, there are several directions for using art in correctional work: psychophysiological (related to the correction of psychosomatic disorders), psychotherapeutic (related to the psycho-emotional sphere), psychological (performing cathartic, regulatory, communicative functions), social and pedagogical (associated with the development of aesthetic needs).

Music therapy is a system of psychosomatic regulation of the functions of a human body using musical-acoustic influences [9]. This set of methods is characterised by ease of use, non-invasiveness, comparatively low cost, and is widely used to regulate heart rate and blood pressure, normalise the functions of internal organs and systems, and correct unfavourable functional conditions of a body. According to another definition, music therapy is the therapeutic use of music and various types of musical activity for the treatment of somatic and mental diseases [10]. Many brain structures are involved in the perception 
and processing of music, and its specific components pitch, rhythm, character, and timbre - are processed by separate neural systems. The successful recognition of music is carried out by the musical memory system, the main structural components of which are the right upper temporal sulcus, the right hippocampus, and the left lower frontal gyrus. The question of what specific attributes of music cause the physiological reactions observed when listening to it was subjected to special analysis. It has been established that the tempo, accentuation, and rhythmic articulation of music are the signs that are most correlated with physiological indicators. The music, which caused more frequent and deeper breathing, a high level of skin conduction, and an increase in heart rate, was characterised by a fast pace, pronounced rhythm, and abrupt style of performance. The authors conclude that the rhythmic aspects of music are the main determinants of physiological responses to listening to it.

To explain the perception of musical rhythms, the concept of "neuronal resonance" is proposed. According to this concept, the perception of the rhythmic aspects of music is mediated by rhythmic flashes of high-frequency neuronal activity in response to musical rhythms. Such outbreaks make communication between nerve centres possible. It is assumed that evolutionary musical rhythms were formed based on motor rhythms that control movements, respiration, and heartbeats [11]. Some teachers apply study methods (communication, motor skills, etc.) with people with special needs, writing songs, and listening in reminiscence/orientation to working with older people, processing and working relaxation and rhythmic ablation for the physical rehabilitation of stroke victims. Music therapy is also used in medical hospitals, oncology centres, schools, alcohol, and drug recovery programs, psychiatric hospitals, and correctional facilities. The responsiveness of the reactions and the exceptional gift of "foreseeing" provoked actions, which appear as immutable artistic skills of a teacher, find their individual expression in such a specific artistic device as pedagogical impromptu or improvisation V.A. Sukhomlinsky emphasised at one time: "It's subtle foresight, the study of the dependencies of many factors and the laws of the pedagogical process allows a true master to instantly change the plan" [12]. A phenomenon called pedagogical improvisation, which not only "animates" the course of the lesson, but also qualitatively transforms the system of relations between a teacher and students, engaging the entire audience in an atmosphere of creative play, is fascinating in these flexible and sometimes indescribable interweaving of the intuitive and the conscious and a phenomenon called pedagogical improvisation manifests itself, which not only "enlivens" the course of a lesson, but also qualitatively transforms relations system of between a teacher and students, involving the entire audience in an atmosphere of creative play, an exciting and unprogrammed search.

The authors emphasise the successful expression of Zh.V. Vaganova: "The motto of an art teacher in each lesson is slightly different than in the previous. This "a little bit" also fills pedagogical activity with life and expressiveness ... And if at the same time, the impromptu is filed in the original art form, then the success of such a teacher is obvious" [13]. Music therapists can work with people who have behaviouralemotional disorders. In order to satisfy the needs of this population group, music therapists adopted current psychological theories and used them as the basis for various types of music therapy. Various models include behavioural therapy, cognitive behavioural therapy, and psychodynamic therapy. A therapist has an ongoing responsibility to assess the extent to which a client achieves the goals of therapy and whether the therapy methods are used to help or interfere with a client. Music therapy can be used with adolescent populations to treat disorders commonly diagnosed in adolescence, such as mood/anxiety disorders and eating disorders or inappropriate behaviour, including suicide attempts, leaving a family, social exclusion from peers, aggression running away, and substance abuse. The goals in treating adolescents with music therapy, especially for those at high risk, often include: wider recognition and understanding of emotions and moods, improving decision-making skills, opportunities for creative expression, reducing anxiety, increasing selfconfidence, improving self-esteem virtues and best listening skills.

Music has many soothing and calming properties that can be used as a sedative in rehabilitation. For example, a patient with chronic pain can reduce the physiological result of stress and distract attention from pain by focusing on music [14]. Music therapy is considered useful for children with spectrum autism, providing repetitive stimuli that are designed to "teach" a brain and other possible responses that may be more beneficial as they get older. In this area of psychotherapeutic research with musical therapeutic specificity, there is a transition from quantitative to qualitative methods based on the theory of the 


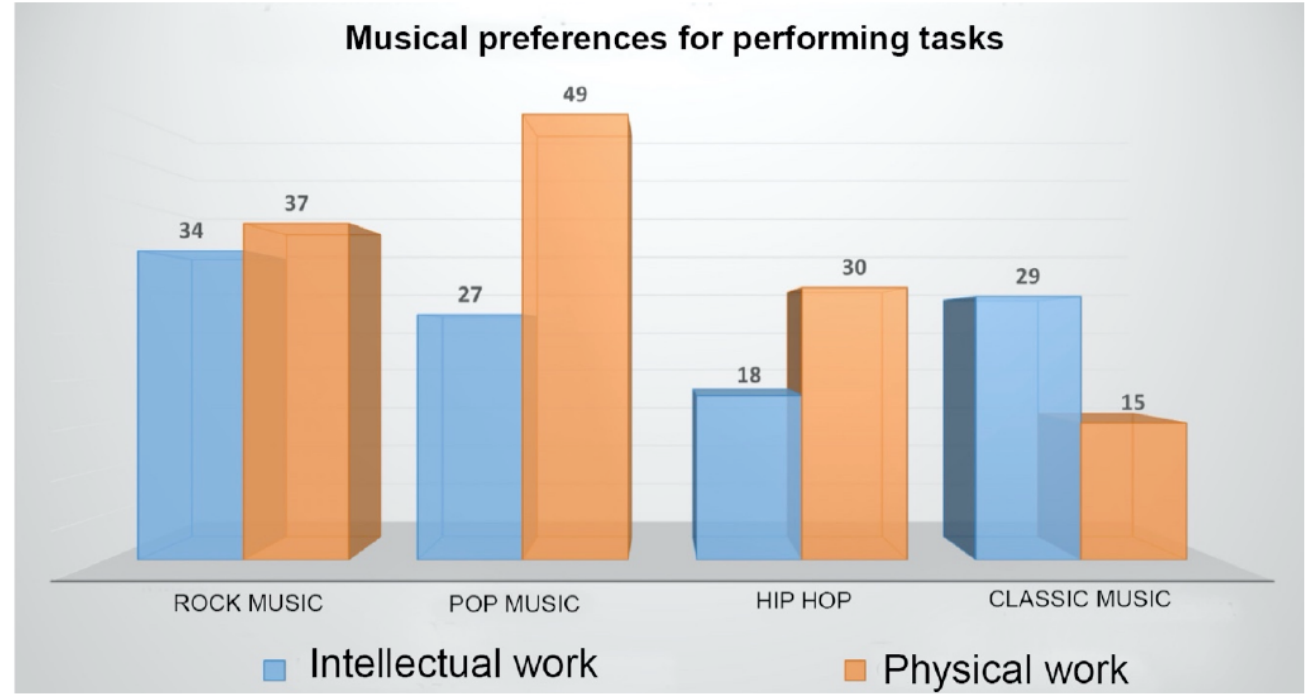

Figure 2: The influence of music on intellectual and physical work.

unconscious, as well as humanistic and existential psychology. A study was conducted among the same students, which made it possible to determine how music affects intellectual and physical work (Figure 2).

Based on Figure 2, classical music has the greatest influence on intellectual work, which confirms the previously analysed theory. A teacher needs to correctly build his lesson and show a high level of artistry for music therapy to have a positive effect on students with psychological disorders.

\section{DISCUSSION}

Music therapy has a positive effect on the development of intelligence in people with psychological disorders. In this, an important role is played by a teacher, his artistry, and his ability to build a lesson and attract students' attention correctly. A teacher should make every effort to maximise the adaptation of students. Proponents of the interactionist trend focus on exploring the other side of adaptation. They attribute adaptation to well-organised methods or methods of life that allow a person to adapt to a new situation and cope with typical problems. Therefore, adaptive behavior characteristics are considered successful decision-making, a clear definition of their future, and a manifestation of the initiative. So, G. Samsonova believes that the signs of effective adaptation are: the ability to establish emotionally rich relationships in the sphere of personal relations; the presence of a feeling of empathy; understanding of the motives of human behaviour; the ability to subtly and accurately reflect changes in relationships; effectiveness in the field of impersonal socio-economic activity in which a person reaches his planned level. J. Piaget considers adaptation in the form of two interconnected operations: accommodation (assimilation of the rules of the environment, "assimilation" to it) and assimilation ("assimilation" to oneself, the environment transformation). In general, adaptation is the process of adapting the body to the environment and achieving harmonious balance with it [15].

In Russian psychology, adaptation processes have been intensively studied in connection with the problems of social transformations. S.V. Shushardzhan believed that through adaptation, optimisation of the functioning of the body systems and balance in the "man - environment" system is achieved $[15,16]$. The author came to this conclusion, considering the possibilities of adaptive mechanisms developed in the process of evolution and providing the possibility of the existence of an organism in constantly changing environmental conditions. A similar approach A.V. Sukharev is developing, according to who the adaptation processes are aimed at achieving a mobile equilibrium state of the system by counteracting the influence of internal and external factors that violate this balance. In a number of studies, social adaptation is considered in relation to the leading activity of an individual and the ability of an individual to solve a problem situation [17]. So, A. Nalchajyan defines social adaptation as a state of a relationship between a person and a group, in which a person, without prolonged external and internal conflicts, productively performs his leading activities, satisfies his sociogenic needs, fully meets the role expectations that the reference group presents to it, experiences a state of 
self-affirmation and freely expresses his creative abilities [17]. Socio-psychological adaptation is a prerequisite for the functioning of society as a single social organism. It involves the inclusion of an individual in the social environment through the acquisition of status and place in society's social structure. Researcher of socio-psychological adaptation A.S. Klyuev this type of adaptation understands as the process of including a person in interaction with the social environment, involving orientation in it, awareness of the problems that arise during this interaction, and finding ways to solve them, choosing the most appropriate activity for it in these conditions to achieve compliance with each other and social environment. Quite complex and ambiguous is the issue of indicators of socio-psychological adaptation [18].

Among the indicators and qualities of the individual's adaptation to the social environment, the researchers note: gaining a status and place in the social structure of society; rationing of funds, finding conditions and forms for the free progressive development of personality; maintaining the stability of an object; the acquisition of a new quality as a result of the variability of adequate protective mechanisms; fluency in verbal and non-verbal means of social interaction; awareness of the activity environment, an individual's ability to cope with stressful situations; attitudes towards active interaction with the social environment; adoption of a social role; productivity, severity of the ability to enjoy life and mental balance; constructive resolution of conflict and stress situations; the ability to take responsibility for their actions, manifestations; successful decision making; manifestation of the initiative; the ability to subtly and accurately reflect changes in relationships; effectiveness in the field of impersonal socio-economic activity; emotionally saturated relationships with people, the presence of empathy; adoption and effective response to social expectations. In other words, in the most general form, such indicators are the state of a person's psychological health and the degree of biological reproduction of a particular social group. This means that adaptation indicators determine the viability and "survival" of both an individual and a group. According to M. Humpal, each age period is characterised by the following indicators: a specific social situation or that particular form of relationship that a child enters with adults in a given period; main, or leading, type of activity; major mental tumours. Considering the emotional development of a younger student, it should be emphasised that from the moment a child goes to school, his emotional development more than before, depends on strangers and the experience that he gains outside a home. Therefore, teachers need to show a high level of artistry [8].

In this article, it is about the fact that a teacher must, by all means, ensure the educational process in such a way that students are comfortable learning music. And in the same turn, do everything possible so that the lessons positively affect all participants in the pedagogical process. Consequently, the need for pedagogical improvisation can also be dictated by the atypical circumstances of the teacher's activities. His artistic training tests his strength, helping him get out of the sometimes dead-end, seemingly unsolvable professional situations. It is improvisational moments that create a state of inspiration, genuine "insight", which, as is known, never distinguishes people who are mediocre, uninteresting in terms of the impulses of artistic activity embedded in them. Such instants seem to erupt outward, splashing out everything that truly constitutes the "core" of creative individuality. In this case, the professional need for pedagogical artistry not only does not weaken but also increases, in connection with the desire to compare the educational process's realities. "Any accidents or surprises," remarks Zh.V. Vaganova on this subject, "in the lesson are "played" by the artistry of a teacher who not only is not afraid of them but even loves, because it causes him to mobilise all creative forces, stimulates fantasy and imagination" [13].

D.E. Wolfe, a graduate, and professor of music at Juilliard School was a pianist and composer who, having seen a child with disabilities react positively to music, abandoned his academic career further to explore the possibilities of music as a treatment. Clive Robbins, a special educator, has partnered with Nordoff for over 17 years researching and studying the effects of music on children with disabilities - first in the UK and then in the United States in the 1950s and 60s. Their pilot projects included placement in intensive care units for children with autism and child psychiatry departments, where they put programs in place for children with mental disorders, emotional disturbances, developmental delays, and other odds. Their success in building communication facilities and relationships with children with cognitive impairment at the University of Pennsylvania led the National Institutes of Health to receive the first grant of this nature, as well as a 5-year study of a "treatment project" [19]. The Nordoff-Robbins approach, based on the belief that everyone is able to 
make sense of and benefit from musical experience, is currently practised by hundreds of psychotherapists internationally. It focuses on healing by creating music using both therapist and client together. Various methods are used to accommodate all the possibilities so that even the low functioning people can participate actively [9].

Gertrude Orff at Kindezentrum München developed another approach known as Orff music therapy. Both clinical conditions of social paediatrics and Orff Schulwerk's approach (school) in music education (developed by German composer Karl Orff) influence this method, which is used with children with developmental problems, delays, and disabilities. The field of social paediatrics was developed after World War II in Germany by Theodor Hellbrügge, who realised that medicine alone could not satisfy the complex needs of mentally disabled children. He was consulted by psychologists, occupational therapists, and other mental health professionals whose knowledge and skills can help diagnose and treat children [20]. Gertrude Orff was asked to develop a form of therapy based on the Orff Schulwerk approach to support patients' emotional development. Elements found in both musical therapeutic and educational approaches include an understanding of holistic musical presentations involving both words, sound, and movement; using music and playing improvisation as providing a creative incentive for a child to explore; Orff used instruments, including keyboards and percussion instruments as a means of participation and interaction for therapeutic purposes; and finally, in the multisensory aspects of music, used by the therapist to meet the specific needs of a child, for example, as feelings and sound of hearing [16]. The theoretical foundations also affect the strong emphasis on social inclusion and parental involvement in the therapeutic process found in social paediatricians [21, 22]. Involving parents in this type of interaction, with their direct involvement or observation of a therapist's technique, equips parents with ideas on how to interact appropriately with their child, thereby contributing to a positive parent-child relationship.

Musical educator and psychotherapist Helen Lindqvist Bonny (1921 - May 25, 2010) developed an approach influenced by humanistic and transpersonal psychological views, known as the Bonny method of guided images in music (GIM) [23]. Guided imagery refers to a technique used in natural and alternative medicine that involves using mental imagery to help with patients' physiological and psychological illnesses.
The practitioner often offers relaxing and focusing images, and through imagination and discussion, seeks to find constructive solutions to manage his problems. Bonnie applied this method to the psychotherapeutic field of music therapy using music as a means of guiding a patient to a higher state of consciousness, where healing and constructive self-awareness can take place. Music is considered a "co-therapist" because of its importance [24, 25]. GIM with children can be used in a one-on-one or group setting and includes a relaxation method, identifying and sharing personal sensory states and improvisation to find oneself, and the growth of the reception. The choice of music is carefully selected for a client, depending on their musical preferences and goals of the session. Usually, a classic work, it should reflect the child's age and attention ability in length and genre, and a full explanation of an exercise should be offered at their level of understanding [26]. The use of guided images with autistic children was found to decrease stereotyped behaviour and hyperactivity, increase attention and ability to follow instructions, as well as increase self-initiated communication, verbal and nonverbal.

In this work, the main focus is on an integrated approach to teaching music. Given the use of active and passive music therapy, which must be thought out by a teacher. Thus, professional orientation is an important aspect of personality orientation, is a complex integrative quality. Musical and pedagogical orientation is a kind of professional orientation of a teacher. The structure of the musical pedagogical orientation includes motivational, emotional-volitional, and cognitive-active components that are specific in nature, reflecting the characteristics of professional activity. Being a dynamically developing personality quality of a teacher-musician, the musical and pedagogical orientation of students can be effectively formed in the university's musical and educational process and affects the quality of training of future specialists.

\section{CONCLUSIONS}

Undoubtedly, pedagogical artistry is the embodiment of the emotionally-shaped beginning of the educational process and gives the opportunity to stay alive, and not to become dry, callous. Thanks to artistry, the activity of a teacher rise to the level of art. With the help of this quality, a teacher has the opportunity to influence not only the minds but also the feelings of students, to convey them the experience of 
an emotional-value attitude to the world. In general, educating the emotional personality culture and pedagogical artistry of future music teachers, a student's inner freedom is taught, plasticity, he is taught to feel himself in space and build a space around him in his successful vocal and stage activities by revealing his creative potential and internally developed empathy opportunities personality. Music therapy is one of the most effective means of promoting the socio-psychological adaptation of a child. It performs many functions: creates a positive emotional mood; promotes the development of communication skills, develops a sense of control, reduces negative emotional states and their manifestations and, thus, provides the process of including a personality of a younger student in interaction with a new social environment for him, involving orientation in it, awareness of the problems that arise during this interaction and finding ways to resolve them, choosing the most appropriate activity for it in these conditions to achieve compliance between himself and the social environment.

Music therapy, as one of the most ancient applied forms of art application in society, in the 21st century, takes on a special format. The intensive development of technologies allows talking about the prospects of this direction in the framework of solving the basic issues of rehabilitation medicine. Simultaneously, according to German researchers, music therapy as science has at least three significant advantages compared to other treatment methods. It does not cause side effects, addiction; it is economically feasible since it requires a minimum of costs with maximum efficiency. Prospects for the development of music therapy are seen. First of all, in the expansion and unification of the information space, efforts should be aimed at achieving proper scientific and practical compliance between art and science representatives. Such an effective dialogue seems to be the key to success in the establishment and recognition of music therapy as a sanogenetic technology on a national scale, which will provide new opportunities for the conscious use of sound as the basis of the considered healing method.

\section{ACKNOWLEDGEMENT}

None.

\section{REFERENCES}

[1] Carpenter SL. Undergraduates' perceived gains and ideas about teaching and learning science from participating in science education outreach programs. Journal of Higher Education Outreach and Engagement 2015; 19(3): 113-146.

Merolla DM, Serpe RT. STEM enrichment programs and graduate school matriculation: The role of science identity salience. Social Psychology of Education 2013; 16(4): 575597.

https://doi.org/10.1007/s11218-013-9233-7

[3] Thompson AN, Talbot RM, Doughty L, Huvard H, Le P, Hartley L, Boyer J. Development and application of the Action Taxonomy for Learning Assistants (ATLAs). International Journal of STEM Education 2020; 7(1): Article number 1 . https://doi.org/10.1186/s40594-019-0200-5

[4] Bakharia A, Corrin L, De Barba P, Kennedy G, Gaševíc D Mulder R, Williams D, Lockyer L. A conceptual framework linking learning design with learning analytics. ACM International Conference Proceeding Series 2016; 4: 329338.

https://doi.org/10.1145/2883851.2883944

[5] Chatti MA, Dyckhoff AL, Schroeder U, Thüs H. A reference model for learning analytics. International Journal of Technology Enhanced Learning 2012; 4(5/6): 318-331. https://doi.org/10.1504/IJTEL.2012.051815

[6] Anders $Y$, Rossbach H-G. Preschool teachers' sensitivity to mathematics in children's play: The influence of math-related school experiences, emotional attitudes, and pedagogical beliefs. Journal of Research in Childhood Education 2015; 29(3): 305-322. https://doi.org/10.1080/02568543.2015.1040564

[7] Zagvyazinsky VM. Methodology and method of didactic research. Moscow: Pedagogika, 1982.

[8] Apraksina OA. From the compiler. Musical education at school. Moscow: Muzyka, 1986.

[9] Humpal M. Thoughts on neurologic music therapy and early intervention. Early Childhood Newsletter 2007; 13(6): 10-11.

[10] Kuzmina NV. Professionalism of a personality of a teacher and master of industrial training. Moscow: Vysshaya Shkola, 1990.

[11] Campbell DJ. Mozart effect. Minsk: Popurri, 1999.

[12] Sukhomlinsky VA. About education. Moscow: Politizdat, 1988.

[13] Vaganova ZhV. The artistry of $s$ teacher as a component of his creative personality. Tyumen: Tyumen State University, 1998.

[14] Samsonov GO. Sound Therapy. Musical wellness technologies. Moscow: Nauka, 2009.

[15] Shushardzhan SV. Music therapy: history and prospects. Moscow: Clinical Medicine, 2000.

[16] Baltabaev MKh. Pedagogical, cultural studies. Almaty: RIK, 2000.

[17] Sukharev AV. Introduction to ethno-functional psychology and psychotherapy: a training manual. Moscow: GASK, 2002.

[18] Klyuev AS. Music therapy: Aesthetic-psychological and clinical aspects. St. Petersburg: SPbSUPSW 2010.

[19] Wolfe DE, Noguchi LK. The use of music with young children to improve sustained attention during a vigilance task in the presence of auditory distractions. Journal of Music Therapy 2009; 46(1): 69-82. https://doi.org/10.1093/jmt/46.1.69

[20] Barenboim LS. Questions of performing arts. Moscow: Muzyka 1962.

[21] Baier F, Decker A-T, Voss T, Kleickmann T, Klusmann U, Kunter M. What makes a good teacher? The relative importance of mathematics teachers' cognitive ability, personality, knowledge, beliefs, and motivation for 
instructional quality. British Journal of Educational Psychology 2019; 89(4): 767-786.

https://doi.org/10.1111/bjep.12256

[22] Gebhard M. Teacher education in changing times: A systemic functional linguistics (SFL) perspective. TESOL Quarterly 2010; 44(4): 797-803.

https://doi.org/10.5054/tq.2010.237335

[23] Hoover JJ, Soltero-González L. Educator preparation for developing culturally and linguistically responsive MTSS in rural community elementary schools. Teacher Education and Special Education 2018; 41(3): 188-202. https://doi.org/10.1177/0888406417753689

[24] Aebersold $M$. The history of simulation and its impact on the future. AACN Advanced Critical Care 2016; 27(1): 56-61. https://doi.org/10.4037/aacnacc2016436
[25] Zhang M, Quintana C. Scaffolding strategies for supporting middle school students' online inquiry processes. Computers and Education 2012; 58(1): 181-196. https://doi.org/10.1016/j.compedu.2011.07.016

[26] Zacharia ZC, Manoli C, Xenofontos N, de Jong T, Pedaste $M$, van Riesen SAN, Kamp ET, Tsourlidaki E. Identifying potential types of guidance for supporting student inquiry when using virtual and remote labs in science. Educational Technology Research and Development 2015; 63(2): 257302.

https://doi.org/10.1007/s11423-015-9370-0

Received on 25-07-2020

Accepted on 18-08-2020

Published on 14-09-2020

DOI: https://doi.org/10.6000/2292-2598.2020.08.03.26

(C) 2020 Sydykova et al.; Licensee Lifescience Global.

This is an open access article licensed under the terms of the Creative Commons Attribution Non-Commercial License (http://creativecommons.org/licenses/by-nc/3.0/) which permits unrestricted, non-commercial use, distribution and reproduction in any medium, provided the work is properly cited. 